\title{
Descrição de um Evaporador de Licor Preto de Fábrica de Celulose por Redes Neurais sem Entradas Atrasadas
}

\author{
Araujo, M. N. ${ }^{1}$; Pinheiro, O. S. ${ }^{2}$; Costa, A. O. S. ${ }^{3}$; Costa Jr, E. F. ${ }^{3}$ \\ 1 Graduando em Engenharia Química \\ 2 Especialista da Celulose Nipo-Brasileira S.A. - CENIBRA \\ 3 Docente do curso de Engenharia Química UFES - Universidade Federal do Espírito Santo, Campus de Alegre, \\ Alegre, ES, Brasil
}

\begin{abstract}
Resumo
O sistema de evaporadores de múltiplo efeito de fábrica de obtenção de celulose Kraft é de suma importância, pois é neste sistema que o licor preto, proveniente do cozimento da madeira, é concentrado para sua posterior queima na caldeira de recuperação. $O$ objetivo deste trabalho é a modelagem desse sistema por meio de redes neurais. As redes neurais são sistemas paralelos de unidades de processamento simples (nodos). Os dados necessários para modelagem foram coletados do banco de dados da empresa CENIBRA e previamente tratados. Os modelos testados utilizaram somente os valores das variáveis independentes (entradas do modelo) coletados no mesmo instante de medição da variável a ser predita.
\end{abstract}

Keywords (Palavras chaves): modelagem empírica, redes neurais, evaporadores de múltiplo efeito.

\section{Introdução}

O objetivo do processo Kraft de produção de celulose é a retirada da lignina (composto químico que confere rigidez à madeira) com o mínimo de degradação das fibras. Uma das mais importantes etapas deste processo é a recuperação química, que tem como objetivos recuperar completamente os reagentes químicos, produzir vapor e energia suficientes para suprir o processo e reduzir significativamente o fluxo de efluentes com potencial poluidor. O sistema de evaporadores de múltiplo efeito é de suma importância nesse processo, pois é nele que o licor preto, proveniente do cozimento da madeira, é concentrado até um teor de 65 a $75 \%$ para sua posterior queima na caldeira de recuperação [1]. Neste contexto, a proposta deste trabalho é a modelagem empírica de um evaporador de múltiplo efeito por redes neurais sem 0 emprego de entradas atrasadas.

As redes neuronais são sistemas paralelos de unidades de processamento simples (nodos) que calculam funções matemáticas. As camadas de nodos são conectadas e cada conexão possui um peso que armazena o conhecimento obtido através do modelo e permite ponderar as informações de entrada recebida em cada nodo. A forma com que os nodos estão ligados, arquitetura da rede, é um parâmetro importante, pois restringe o tipo de problema que pode ser tratado $[2,3]$.

O treinamento é um processo no qual a rede tem seus pesos ajustados por meio de um algoritmo especifico de aprendizagem. A obtenção de uma rede neuronal satisfatória está correlacionada com a disponibilidade de dados experimentais suficientes para realização desta etapa [2].

\section{Materiais e Métodos}

Após definir o sistema e as variáveis necessárias para descrição do mesmo. Os dados foram então coletados do banco de dados da empresa CENIBRA, por um período de 10 dias com intervalo de 1 minuto.

O programa utilizado para treinamento, validação e seleção das redes foi o software STATISTICA 9.1.

\section{Resultados}

Os dados duplicados da variável a ser prevista pelas redes, concentração na saída (Cs) do vaso flash 
localizado após os evaporadores, foram excluídos para diminuir os efeitos da "banda morta" (o banco de dados da empresa não armazena variações nas variáveis medidas interiores a uma determinada porcentagem de variação das mesmas, definida como banda morta). Mais além, foi realizada uma análise gráfica das medições de cada variável considerada, utilizando histogramas como os da figura 1.
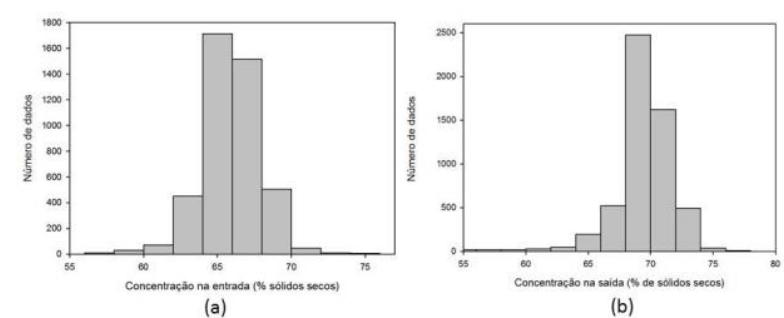

(b)
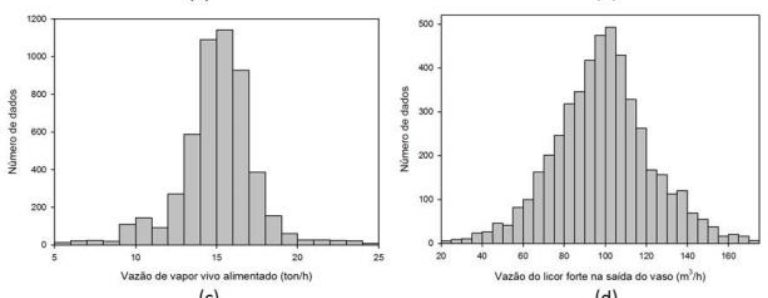

(d)

Figura 1: Histograma para: (a) Concentração na entrada do evaporador (Ce); (b) Concentração na saída (Cs); (c) Vazão do vapor vivo alimentado (Qvv); (d) Vazão do licor forte na saída do vaso flash (Qls).

Assim, definiu-se para cada variável uma faixa operacional a ser empregada no desenvolvimento e validação das redes. Após retirar as saídas repetidas e restringir as faixas de dados como na Tabela 1, o total de 37440 dados foi reduzido a 4075 dados.

Tabela 1: Faixas operacionais empregadas no desenvolvimento e validação das redes.

\begin{tabular}{ccc}
\hline Variáveis & $\begin{array}{c}\text { Valor } \\
\text { mínimo }\end{array}$ & $\begin{array}{c}\text { Valor } \\
\text { máximo }\end{array}$ \\
\hline Cs(\%) & 64,0 & 74,0 \\
\hline Vazão de vapor (ton/h) & 9,0 & 19,0 \\
\hline Vazão de saída $\left(\mathrm{m}^{3} / \mathrm{h}\right)$ & 54,0 & 154,0 \\
\hline Nível do evaporador $(\%)$ & 38,0 & 54,0 \\
\hline Concentração na entrada $(\%)$ & 58,0 & 72,0 \\
\hline Temperatura na saída $\left({ }^{\circ} \mathrm{C}\right)$ & 103,0 & 115,0 \\
\hline Pressão do vapor $\left(\mathrm{Kgf} / \mathrm{cm}^{2}\right)$ & 2,5 & 3,6 \\
\hline Temperatura do vapor $\left({ }^{\circ} \mathrm{C}\right)$ & 143,0 & 166,0 \\
\hline Pressão no vaso flash $\left(\mathrm{Kgf} / \mathrm{cm}^{2}\right)$ & $-0,24$ & 0,01 \\
\hline
\end{tabular}

A melhor rede obtida possui 7 entradas e 7 neurônios na camada intermediária. Na predição, têm-se erros absolutos médios de 0,89534 para treinamento, 0,90067 para teste, 0,91680 para validação, considerando-se uma faixa de variação de Cs entre 64,0 e $74,0 \%$ de sólidos secos, e coeficiente de determinação $\left(R^{2}\right)$ igual a 0,40 .

\section{Conclusões}

A partir do baixo desempenho das redes estáticas, conclui-se que a hipótese da construção de um modelo por redes neurais sem o uso de entradas atrasadas foi rejeitada. Este resultado é fisicamente explicado pelo fato de o evaporador não operar em regime estacionário e, devido às suas dimensões, possuir uma dinâmica que não pode ser desprezada. Desta forma, pretende-se gerar redes dinâmicas para este equipamento por meio da inserção de variáveis atrasadas na rede.

\section{Agradecimentos}

Os autores agradecem a FAPES pela bolsa IC e de pesquisador capixaba e ao CNPq pela bolsa de produtividade DTI.

\section{Referências}

[1] ALMEIDA, A. M. Modelagem, Simulação e Controle de um Sistema de Evaporação Múltiplo Efeito de Licor Negro. Monografia (Trabalho de Conclusão de Curso) Faculdade de Telêmaco Borba, Paraná, 2009.

[2] BRAGA, A. P.; LUDEMIR, T. B.; CARVALHO, FERREIRA, A. C. P. L. Redes neurais e artificiais: Teoria e aplicações, Editora LTC. 2000. 1 - 29.

[3] COSTA, A. O. S. Alternativas para o controle de um sistema de evaporadores de múltiplo efeito. Tese (Mestrado em ciências em engenharia Química), Programa de pós-graduação de engenharia da Universidade Federal do Rio de Janeiro, Rio de Janeiro, 2000. 